\title{
Recorded quality of care for depression in general practice: an observational study
}

\author{
Sivatharan Vedavanam, Nicholas Steel, Joanne Broadbent, Susan Maisey, Amanda Howe
}

\author{
ABSTRACT \\ Background \\ Depression is a leading cause of disease and disability \\ internationally, and is responsible for many primary \\ care consultations. Little is known about the quality of \\ primary care for depression in the UK. \\ Aim \\ To determine the prevalence of good-quality primary \\ care for depression, and to analyse variations in quality \\ by patient and practice characteristics.

\section{Design of study} \\ Retrospective observational study. \\ Setting \\ Eighteen general practices in England. \\ Method \\ Medical records were examined for 279 patients. The \\ percentage of eligible participants diagnosed with \\ depression who received the care specified by each of \\ six quality indicators in 2002 and 2004 was assessed. \\ Associations between quality achievement and age, \\ sex, patient deprivation score, timepoint, and practice \\ size were estimated using logistic regression.

\section{Results} \\ There was very wide variation in achievement of \\ different indicators (range 1-97\%). Achievement was \\ higher for indicators referring to treatment and follow- \\ up than for indicators referring to history taking. \\ Achievement of quality indicators was low overall \\ (37\%). Quality did not vary significantly by patient or \\ practice characteristics.

\section{Conclusion} \\ There is substantial scope for improvement in the \\ quality of primary care for depression, if the highest \\ achievement rates could be matched for all indicators. \\ Given the lack of variation by practice characteristics, \\ system-level and educational interventions may be the \\ best ways to improve quality. The equitable distribution \\ of quality by patient deprivation score is an important \\ achievement that may be challenging to maintain as \\ quality improves.

\section{Keywords} \\ depression; primary health care; quality indicators; \\ quality of health care.
}

\section{INTRODUCTION}

Every year $6 \%$ of UK adults will experience an episode of depression, with a lifetime incidence of $15 \% .{ }^{1}$ Depression is more common than diabetes and asthma, and is responsible for $15 \%$ of general practice consultations. ${ }^{2}$ About $90 \%$ of episodes of depression are managed in primary care. ${ }^{3}$ The annual cost of depression in England alone is estimated at $£ 9$ billion in 2000 , of which $90 \%$ was attributable to an estimated 110 million lost working days. ${ }^{4}$ Depression has been shown to be an independent risk factor for cardiovascular disease,${ }^{5}$ and is a major international cause of disease and disability. ${ }^{6}$

High quality of care for depression in primary care settings is clearly important to minimise the morbidity caused by such a prevalent condition. The National Institute for Health and Clinical Excellence (NICE) has recognised the need for depression to be managed better, with updated guidelines being introduced in 2008/2009. ${ }^{7}$ The Royal College of General Practitioners has a Mental Health Task Force which aims to improve management of depressive disorders in primary care settings, and which has called for incentives to improve primary mental health care. ${ }^{8}$ The National Service Framework for Mental Health aimed to drive up quality and reduce unacceptable variations in health and social services. ${ }^{9}$

There is considerable literature about approaches

$S$ Vedavanam, BSc, MBBS, F2 doctor; N Steel, PhD, MRCGP, FFPH, senior lecturer; J Broadbent, $M S c, P h D, M F P H$, specialist trainee in public health; $S$ Maisey, $M S c$, research associate; $A$ Howe, MA, MEd, MD, FRCGP, professor, Primary Care Group, School of Medicine, University of East Anglia, Norwich.

Address for correspondence

Dr Nicholas Steel, Primary Care Group, School of Medicine, Health Policy and Practice, University of East Anglia, Norwich, NR4 7TJ. E-mail: n.steel@uea.ac.uk

Submitted: 21 April 2008; Editor's response: 12 June 2008; final acceptance: 27 August 2008.

(C)British Journal of General Practice

This is the full-length article of an abridged version published in print. Cite this article as: Br J Gen Pract 2009; DOI: 10.3399/bjgp09X395085 
to managing depression in primary care, but it is not consistent in its findings. Little information is available about the prevalence of good-quality health care for depression. A systematic review by Seddon et al of quality of care in general practice reported that treatment doses for depression were inadequate, but this was over 10 years ago. ${ }^{10}$

Robust quality indicators have been previously developed, and all the quality indicators to be used in this study came from at least one of three sources: NICE, ${ }^{11}$ Quality Indicators for General Practice developed at the National Primary Care and Research Development Centre, ${ }^{12}$ and RAND health indicators adapted for the UK and previously published in Quality and Safety in Health Care $(\mathrm{QSHC})^{13}$ (Table 1). These indicators have been validated by independent expert panels, which included British GPs.

Using existing quality indicators, the aim of this study was to determine the prevalence of goodquality primary care in the UK for depression at two time points, and to analyse the variations in quality of care by patient and practice characteristics.

\section{METHOD}

\section{Participants}

Data collected were part of a larger study involving 1156 patients with four chronic conditions where quality was assessed over time. ${ }^{14}$ Practices in Norfolk primary care trusts were selected to give equal numbers in each of three groups stratified by national deprivation, to improve generalisability. Practice deprivation scores were calculated as weighted means based on the deprivation scores of registered patients at each of the practices. ${ }^{15}$ Quality indicators were measured in 18 general practices in Norfolk; and between 20 and 40 randomly selected eligible patients at each practice were contacted for permission to examine their full records.

\section{Data collection}

Data were extracted from electronic and paper records for six indicators in depression for 6 months between April and September 2002 and again for 6 months from April to September 2004. Patient deprivation scores were estimated by using the National Statistics Postcode Directory ${ }^{16}$ to find each Lower Super Output Area (LSOA) of residence, and then using the Index of Multiple Deprivation 2007 rank of the LSOA as an indicator of deprivation. ${ }^{17}$ The criteria used to identify depression are given in Box 1 , and details of READ codes used are given in Appendix 1. Depressed mood can occur as part of other diagnoses; for example, mixed-anxiety or borderline personality disorder may have been associated diagnoses.

\section{How this fits in}

Depression is a prevalent disease that is frequently treated in general practice, yet little is known about the quality of care for depression. This study assessed whether the recorded quality of primary care for depression accorded with quality indicators. Substantial variation was found in quality of care by indicator, and equitable distribution of quality. Initiatives are necessary to improve quality of care.

\section{Data analysis}

Quality of healthcare scores were calculated for each indicator as the percentage of eligible patients for whom the indicator was achieved. Associations with patient and practice characteristics were estimated using logistic regression models. The outcome variable was quality indicator achievement, and the explanatory variables were: age group $(18-37,38-55$, and $\geq 56$ years), sex, patient deprivation group ( $1=$ least deprived, 3 = most deprived), practice size (1 = smallest, 3 = largest), and timepoint (2002 or 2004). Appropriate adjustments were made for clustering at practice levels using a random hierarchial effects model. All analyses were conducted using STATA (version 9.1 SE, Texas US). The numbers of participants achieving indicators Depression(D)2,

Table 1. Quality indicators and source.

\begin{tabular}{|c|c|c|}
\hline Indicator category & Quality indicator & Source(s) of indicator \\
\hline \multirow[t]{2}{*}{ History taking } & $\begin{array}{l}\text { (D1) Percentage of patients receiving a } \\
\text { diagnosis of a new depression episode, } \\
\text { for whom presence or absence of thoughts } \\
\text { about suicide is recorded at diagnosis. }\end{array}$ & $\begin{array}{l}\mathrm{NICE}^{11} \\
\mathrm{QSHC}^{13} \\
\mathrm{QIGP}^{12}\end{array}$ \\
\hline & $\begin{array}{l}\text { Percentage of patients assessed for } \\
\text { depression, whose notes contained a } \\
\text { record that they were asked about: } \\
\text { (D2) alcohol use } \\
\text { (D3) substance misuse } \\
\text { (D4) current medication. }\end{array}$ & $\mathrm{QIGP}^{12}$ \\
\hline Treatment & $\begin{array}{l}\text { (D5) Percentage of patients diagnosed } \\
\text { with clinical depression, whose notes } \\
\text { contained a record that they were offered } \\
\text { antidepressant treatment or talking } \\
\text { treatment within } 2 \text { weeks of diagnosis } \\
\text { unless within that period the patient } \\
\text { has improved, or unless the patient } \\
\text { has substance abuse or dependence. }\end{array}$ & $\begin{array}{l}\text { QSHC }^{13} \\
\text { QIGP }^{12}\end{array}$ \\
\hline Follow-up & $\begin{array}{l}\text { (D6) Percentage of patients } \\
\text { receiving treatment for a new } \\
\text { depression episode, whose } \\
\text { notes contain a record that they } \\
\text { were offered a follow-up appointment } \\
\text { within } 4 \text { weeks of first treatment. }\end{array}$ & $\begin{array}{l}\mathrm{NICE}^{11} \\
\mathrm{QSHC}^{13} \\
\mathrm{QIGP}^{12}\end{array}$ \\
\hline
\end{tabular}

NICE = National Institute for Health and Clinical Excellence. QHSC = Quality and Safety in Health Care. QIGP $=$ Quality Indicators for General Practice. 


\section{Box 1. Criteria for inclusion in depression group.}

- Patients aged 18 years or over, with a READ diagnosis code for endogenous or exogenous depression.

- Patients with a symptom code for 'depressed' or 'depressive episode', PLUS positive evidence in the notes of a previous episode of depression, free text record of a diagnosis of depression, or specific evidence of specific treatment for depression, in the 6 months after 1 April 2002 and 2004 respectively.

- Patients diagnosed with depression or with antidepressant prescribed in the year prior to 1 April 2002 and 2004 respectively were excluded, so that only new depression episodes were included.

See Appendix 1 for further READ code inclusion criteria.

D3, and D4 were so low (fewer than 25 patients) that regression analysis was not conducted on these indicators.

\section{RESULTS}

A total of 515 patients were invited to take part, of whom 279 (53\%) consented. Sample characteristics are given in Table 2.

Mean age of participants was 50 years, and $72 \%$ were female, compared with a mean age of 45 years and $69 \%$ female in the population invited to participate. The practice deprivation scores ranged from $7 \%$ to $73 \%$ of the full range of national practice deprivation scores.

There was considerable variation between quality indicators, from $1 \%$ to $97 \%$ (Table 3). The overall

Table 2. Sample characteristics.

\begin{tabular}{lccc}
\hline Non-patient variables & Description & & \\
\hline \multirow{4}{*}{ Practice size } & & $n$ & $\%$ \\
& Small (501-5000 patients) & 43 & 15 \\
& Medium (5001-10 000 patients) & 139 & 50 \\
& Large ( 10 000 patients) & 97 & 34 \\
& Total & 279 & 100 \\
\hline Timepoint & 2003 & 145 & 52 \\
& 2005 & 134 & 48 \\
& Total & 279 & 100 \\
\hline Patient variables & & & \\
\hline \multirow{3}{*}{ Patient LSOA } & High (IMD 106-10 972) & $n$ & $\%$ \\
deprivation & Medium (IMD 11 165-20 432) & 92 & 33 \\
& Low (IMD 20 642-32 306) & 94 & 34 \\
& Total & 90 & 32 \\
& & 276 & 99 \\
Patient LSOA deprivation & Rank & Median & Range \\
\hline \multirow{4}{*}{ Age } & & 18007 & $106-32306$ \\
\hline \multirow{2}{*}{ Sex } & Years & Median & Range \\
& & 48 & $19-95$ \\
\hline
\end{tabular}

$L S O A=$ Lower Super Output Area. IMD = Indices of Multiple Deprivation 2007 rank. achievement was $37 \%$ (95\% confidence interval = 35 to $40 \%)$.

For indicators D2, D3, and D4 relating to history taking, achievement was less than $10 \%$. Achievement of indicators D5 and D6, relating to recording treatment and follow-up was considerably higher (78-97\%).

\section{DISCUSSION}

\section{Summary of main findings}

Recorded quality of care for depression in primary care varied substantially according to the indicator measured. Care was provided equitably, with no variation in quality by patient or practice characteristics.

\section{Strengths and limitations of the study}

This study has a number of strengths. The indicators in the study have been through rigorous development processes, ${ }^{11-13}$ and so differences in professional values are unlikely to account for the low scores in D1 to D4. Data were collected by hand searching of both electronic and paper patient records, using clear criteria. The practices in this study were broadly representative of the English national range of socioeconomic deprivation. ${ }^{14}$ The quality indicators in this paper refer to processes of health care rather than outcomes, as processes have fewer problems with case mix bias than outcome measures, are more sensitive measures of quality than outcomes, and are more clearly linked to any action that should be taken to improve quality. ${ }^{18,19}$

One limitation of this study is that the method relied on care being recorded in the notes, and it is possible that care was delivered but not recorded. This would underestimate quality of care. However, it can be argued that recording of care is essential in team-based care for chronic disease ${ }^{20}$ and that without this one cannot assume any action was taken.

One of the study's selection criteria related to whether the patient was on treatment, and this may 
Table 3. Achievement of quality indicators by sample characteristics.

\begin{tabular}{|c|c|c|c|c|c|c|c|c|}
\hline \multicolumn{4}{|c|}{ Quality indicators ${ }^{\mathrm{a}}$} & \multicolumn{5}{|c|}{ Sample characteristics } \\
\hline $\begin{array}{l}\text { Quality } \\
\text { indicator }\end{array}$ & $\begin{array}{c}\text { Patients } \\
\text { eligible, } \\
n\end{array}$ & $\begin{array}{l}\text { Patients } \\
\text { for whom } \\
\text { indicators were } \\
\text { achieved, } n\end{array}$ & $\begin{array}{c}\text { Quality } \\
\text { indicators } \\
\text { achieved, } \\
\%(95 \% \mathrm{Cl})\end{array}$ & $\begin{array}{c}\text { Age group } \\
\text { versus } 18-37 \text {, } \\
\text { OR }(95 \% \mathrm{Cl})\end{array}$ & $\begin{array}{c}\text { Sex } \\
\text { versus males, } \\
\text { OR }(95 \% \mathrm{Cl})\end{array}$ & $\begin{array}{c}\text { Timepoint } \\
\text { versus 2003, } \\
\text { OR (95\% Cl) }\end{array}$ & $\begin{array}{l}\text { Practice size } \\
\text { versus smallest, } \\
\text { OR }(95 \% \mathrm{Cl})\end{array}$ & $\begin{array}{l}\text { Patient IMD } \\
2007 \text { rank versus } \\
\text { least deprived, } \\
\text { OR }(95 \% \mathrm{Cl})\end{array}$ \\
\hline D1 & 279 & 99 & 35 (30 to 41$)$ & 0.68 (0.43 to 1.11$)$ & 0.58 (0.31 to 1.11$)$ & 1.05 (0.60 to 1.83$)$ & $1.12(0.74$ to 1.68$)$ & 1.17 (0.87 to 1.57$)$ \\
\hline D2 & 279 & 24 & 9 (6 to 13$)$ & b & b & b & b & b \\
\hline D3 & 279 & 4 & 1 (0 to 4$)$ & b & $\mathrm{b}$ & $\mathrm{b}$ & $\mathrm{b}$ & $\mathrm{b}$ \\
\hline D4 & 279 & 12 & 4 (2 to 7$)$ & b & b & b & $\mathrm{b}$ & b \\
\hline D5 & 277 & 271 & 97 (95 to 99) & 1.02 (0.56 to 1.86$)$ & 1.28 (0.21 to 7.62$)$ & 1.81 (0.29 to 11.36$)$ & 1.14 (0.37 to 3.49$)$ & 1.30 (0.50 to 3.38 ) \\
\hline D6 & 271 & 213 & 78 (73 to 83 ) & $0.79(0.48$ to 1.28$)$ & 0.59 (0.29 to 1.19$)$ & 0.97 (0.64 to 1.49$)$ & $0.93(0.55$ to 1.54$)$ & 1.14 (0.79 to 1.65 ) \\
\hline
\end{tabular}

${ }^{a}$ For a full list of quality indicator, see Table 1. ${ }^{b}$ Excluded from further analysis due to low numbers (fewer than 25 achieved quality indicators). OR = odds ratios. IMD = Indices of Multiple Deprivation.

account for the high score of indicator D5. Time constraints for a consultation regarding a new diagnosis of depression have been reported, ${ }^{21}$ and this may lead to selective recording of information.

The indicators used in this paper refer to clinical effectiveness, which is only part of primary healthcare for depression. Within each group of 'eligible' patients, there may be some who, on clinical assessment, would not require the specified intervention. However, higher scores at population level clearly represent better quality of care for that indicator.

The response rate $(53 \%)$ is comparable to other studies involving patients with depression. ${ }^{22}$ This relatively low response may be a source of bias if non-responders differed systematically from responders, but they were broadly similar with respect to age and sex.

\section{Comparison with existing literature}

Data from the US by Wells et al concur that quality of depression care is low to moderate in primary care settings ${ }^{23}$ Research from the US suggests that when quality improvement programmes were initiated in primary care settings, such as training staff to identify depression, mental health outcomes and employment retention rates improved. ${ }^{24}$

The lack of a link between quality of care for depression and patient deprivation in general practice is supported by Weich et $a l,{ }^{25}$ although they report those without educational qualifications were less likely to receive psychological treatments.

This study suggests that once a diagnosis is made, quality of care is equitable (that is, it does not differ between different patient groups or practices), but numbers of patients to differentiate between subgroups was low. It is not possible to comment, from the data in this study, on whether some patients (for example, with lower socioeconomic status or education) were less likely to be diagnosed. It cannot be assumed that equity of care is the same as equity of workload: patients in poorer areas may have fewer GPs with higher consultation rates, who therefore have to work harder to achieve the same level of care. ${ }^{26}$ Longer consultations may be associated with better patient outcomes. ${ }^{27}$ Average consultation length is shorter in deprived areas, and high socioeconomic deprivation is associated with a higher prevalence of psychologically distressed patients. ${ }^{28}$ This combination of higher prevalence with greater demand and potential limits on capacity and access to care follows Tudor Hart's 'inverse care law'. ${ }^{29}$

\section{Implications for clinical practice}

The substantial variation in the quality of primary care for depression by quality indicator, but not by practice or patient characteristics, suggests that there is considerable scope for reduction in psychiatric morbidity, if the highest levels of achievement found could be replicated for indicators where quality was poor. The equitable distribution of quality suggests that system-level changes may be indicated, as nearly all practices performed poorly on some indicators. Educational initiatives that enhance doctors' skills and motivation may help improve care and the recording of it. ${ }^{30}$

When these data were collected, no indicators for mild to moderate depression were included in the Quality and Outcomes Framework (QOF) of the incentive scheme for UK general practices. ${ }^{31}$ The 2006-2007 QOF includes two indicators referring to the use of validated tools for diagnosis and screening, and $79-85 \%$ achievement was reported. ${ }^{32}$ The indicators used in this study go beyond these case finding indicators to cover history taking, treatment, and follow-up for depression. 
This is an initial assessment of quality of depression care in general practice. Research involving more patients and quality indicators, as well as different approaches to measuring quality (for example, consultation analysis) is needed. The quality indicators used in this study are a starting point, and further research is needed to determine which indicators should be used, especially as patient groups and doctors differ in their choices. ${ }^{33}$

This study has shown that it is feasible to measure quality of primary care for depression across a range of interventions, and found that quality was highly variable. Interventions are required to improve the quality of care for low-scoring quality indicators, without losing the equitable distribution of care found in this study.

\section{Online version}

Additional information can be found in the online version of this article: http://www.rcgp.org.uk/bjgp

\section{Funding body}

Sivatharan Vedavanam was funded in an academic F2 job by Norfolk \& Norwich University Hospital NHS Trust. Nicholas Steel was funded by a Primary Care Researcher Development Award from the UK National Coordinating Centre for Research Capacity Development (RDA03/21). Norwich Primary Care Trust Research Office contributed to practice expenses for this project

\section{Ethical approva}

The Norwich Research Ethics Committee provided ethical approval of the study (REC 05/Q0101/37)

\section{Competing interests}

The authors have stated that there are none

\section{Acknowledgements}

We thank all the practice staff who helped with the study.

\section{Discuss this article}

Contribute and read comments about this article on the Discussion Forum: http://www.rcgp.org.uk/bjgp-discuss

\section{REFERENCES}

1. National Institute for Health and Clinical Excellence. Scope. Depression: management of depression in adults in primary and secondary care (update). http://www.nice.org.uk/nicemedia/pdf/ DPSC_Scope_for_Consultation_240807.pdf (accessed 19 Sept 2008).

2. Scottish Executive. Social focus on men and women 2002, Scottish Executive National Statistics

http://www.scotland.gov.uk/stats/sfwm/docs/sfwm-06.asp (accessed 17 Dec 2008)

3. Scott J, Thorne A, Horn P. Effect of a multifaceted approach to detecting and managing depression in primary care. BMJ 2002, 325(7370): 951-954

4. Thomas CM, Morris S. Cost of depression among adults in England in 2000. Br J Psychiatry 2003; 183: 514 -519.

5. Hippisley-Cox J, Fielding K, Pringle M. Depression as a risk factor for ischaemic heart disease in men: population based case-control study. BMJ 1998; 316(7146): 1714-1719.

6. World Health Organization. Depression http://www.who.int/mental_health/management/depression/defini tion/en/ (accessed 19 Sept 2008).

7. National Institute for Health and Clinical Excellence. Depression: management of depression in primary and secondary care - NICE guidance. http://www.nice.org.uk/guidance/CG23 (accessed 19 Sept 2008).

8. Cameron I. New GMS contract failing mental health patients, says RCGP. http://www.pulsetoday.co.uk/story.asp?storyCode
$=4006490$ \&sectioncode $=23$ (accessed 19 Sept 2008).

9. Department of Health. The national service framework for mental health. London: Department of Health, 1999.

10. Seddon ME, Marshall MN, Campbell SM, Roland MO. Systematic review of studies of quality of clinical care in general practice in the UK, Australia and New Zealand. Qual Health Care 2001; 10(3): 152-158.

11. National Institute for Health and Clinical Excellence. http://www.nice.org.uk/ (accessed 19 Sept 2008).

12. Marshall M, Campbell S, Hacker J, Roland M. Quality indicators for general practice. A practical guide for health professionals and managers. London: Royal Society of Medicine Press, 2002.

13. Steel N, Melzer D, Shekelle PG, et al. Appendix to 'Developing quality indicators for older adults: transfer from the USA to the UK is feasible'. Qual Saf Health Care 2004; 13(4): 260-264.

14. Steel N, Maisey S, Clark A, et al. Quality of clinical primary care and targeted incentive payments. Br J Gen Pract 2007; 57(539): 449-454.

15. Noble M, Wright G, Dibben C, et al. The English indices of deprivation 2004. Wetherby: ODPM Publications, 2004.

16. Office for National Statistics. National Statistics Postcode Directory. London: Office for National Statistics, 2007. http://www.ons.gov.uk/about-statistics/geography/products/geogproducts-postcode/nspd/index.html (accessed 17 Dec 2008).

17. Department for Communities and Local Government. The English indices of deprivation 2007. London: The Stationery Office, 2007.

18. Lilford RJ, Brown CA, Nicholl J. Use of process measures to monitor the quality of clinical practice. BMJ 2007; 335(7621): 648-650.

19. Mant J, Hicks N. Detecting differences in quality of care: the sensitivity of measures of process and outcome in treating acute myocardial infarction. BMJ 1995; 311(7008): 793-796.

20. Hamilton WT, Round AP, Sharp D, Peters TJ. The quality of record keeping in primary care: a comparison of computerised, paper and hybrid systems. Br J Gen Pract 2003; 53(497): 929-933.

21. Mellor D, Davison T, McCabe M, et al. Satisfaction with general practitioner treatment of depression among residents of aged care facilities. J Aging Health 2006; 18(3): 435-437.

22. Ayuso-Mateos JL, Vazquez-Barquero JL, Dorwick C, et al. Depressive disorders in Europe: prevalence figures from the ODIN study. Br J Psychiatry 2001; 179: 308-316.

23. Wells K, Schoenbaum M, Unutzer J, et al. Quality of care for primary care patients with depression in managed care. Arch Fam Med 1999; 8(6): 529-536.

24. Wells KB, Sherbourne C, Schoenbaum M, et al. Impact of disseminating quality improvement programs for depression in managed primary care: a randomised controlled trial. JAMA 2000 283(2): 212-220

25. Weich S, Nazareth I, Morgan L, King M. Treatment of depression in primary care. Br J Psychiatry 2007; 191: 164-169.

26. Heath I, Hippisley-Cox J, Smeeth L. Measuring performance and missing the point? BMJ 2007; 335(7629): 1075-1076.

27. Freeman G, Horder J, Howie J, et al. Evolving general practice consultation in Britain: issues of length and context. BMJ 2002; 324(7342): 880-882.

28. Stirling A, Wilson P, McConnachie A. Deprivation, psychological distress, and consultation length in general practice. Br J Gen Pract 2001; 51(467): 456-460.

29. Hart J. The inverse care law. Lancet 1971; 1(7696): 405-412.

30. Howe A. Detecting depression in the elderly — what will improve our performance? Br J Gen Pract 1996; 46(410): 207-208.

31. General Practitioners Committee BMA, The NHS Confederation. Investing in general practice. The new general medical services contract. London: The NHS Confederation, 2003.

32. The NHS Information Centre. http://www.ic.nhs.uk/ (accessed 15 Dec 2008).

33. Shield T, Campbell S, Rogers A, et al. Quality indicators for primary care mental health services. Qual Saf Health Care 2003; 12(2): 100-106. 


\section{Appendix 1. Full READ code inclusion criteria for electronic searches}

Setting the criteria for this sample was challenging, because of the variety of ways GPs recorded depression. The initial search criteria were very inclusive. A few patients who had only a symptom code and no corroboration in text notes or from referral letters or prescriptions were manually excluded on detailed notes review, as were a few who had an episode of depression that had clearly started before the qualifying period, but who had not been prescribed medication in the 12-month run up.

The full criteria for the electronic searches are given below.

Depression 2002

- Currently registered

- AND date of birth before $1 / 4 / 1984$

- AND with READ code E11 ... to E11z anywhere in record between 1/4/2002 and 30/9/2002

o OR with READ code E130 anywhere in record between 1/4/2002 and 30/9/2002

o OR with READ code E135 anywhere in record between 1/4/2002 and 30/9/2002

o OR with READ code E291 anywhere in record between 1/4/2002 and 30/9/2002

o OR with READ code E2B... to E2Bz anywhere in record between 1/4/2002 and 30/9/2002

o OR with READ code IB17 anywhere in record between 1/4/2002 and 30/9/2002

o OR with READ code 1B1U anywhere in record between 1/4/2002 and 30/9/2002

o OR with READ code Eu32... to Eu32z anywhere in record between 1/4/2002 and 30/9/2002

EXCLUDE patients with

- READ code $d 6 \ldots$ to $d 6 z$ anywhere in record between $1 / 4 / 2001$ and $31 / 3 / 2002$

- OR with READ code $d 7 \ldots$ to $d 7 z$ anywhere in record between $1 / 4 / 2001$ and 31/3/2002

o OR with READ code d8... to d8z anywhere in record between 1/4/2001 and 31/3/2002

o OR with READ code d9... to $d 9 z$ anywhere in record between $1 / 4 / 2001$ and $31 / 3 / 2002$

o OR with READ code da... to daz anywhere in record between 1/4/2001 and 31/3/2002

o OR with BNF code 4.2.3 anywhere in record between 1/4/2001 and 31/3/2002

o OR with BNF code 4.3 anywhere in record between 1/4/2001 and 31/3/2002

Depression 2004

- Currently registered

- AND date of birth before 1/4/1986

- AND with READ code E11... to E11z anywhere in record between 1/4/2004 and 30/9/2004

o OR with READ code E130 anywhere in record between 1/4/2004 and 30/9/2004

o OR with READ code E135 anywhere in record between 1/4/2004 and 30/9/2004

o OR with READ code E291 anywhere in record between 1/4/2004 and 30/9/2004

O OR with READ code E2B... to E2Bz anywhere in record between 1/4/2004 and 30/9/2004

o OR with READ code 1B17 anywhere in record between 1/4/2004 and 30/9/2004

o OR with READ code 1B1U anywhere in record between 1/4/2004 and 30/9/2004

o OR with READ code Eu32... to Eu32z anywhere in record between 1/4/2004 and 30/9/2004

- EXCLUDE patients with

- READ code $d 6 \ldots$ to $d 6 z$ anywhere in record between $1 / 4 / 2003$ and $31 / 3 / 2004$

o OR with READ code $d 7 \ldots$ to $d 7 z$ anywhere in record between $1 / 4 / 2003$ and 31/3/2004

o OR with READ code d8... to d8z anywhere in record between 1/4/2003 and 31/3/2004

o OR with READ code d9... to d9z anywhere in record between 1/4/2003 and 31/3/2004

o OR with READ code da... to daz anywhere in record between 1/4/2003 and 31/3/2004

o OR with BNF code 4.2.3 anywhere in record between 1/4/2003 and 31/3/2004

o OR with BNF code 4.2 anywhere in record between 1/4/2003 and 31/3/2004

$B N F=$ British National Formulary 